\title{
EVALUATION OF INTERACTION ENERGIES AND THERMODYNAMIC PROPERTIES IN BINARY MIXTURE OF REACTIVE ORANGE 107 DYE + TRITON X-114 SURFACTANT AT 303.15, 313.15 \& 323.15K: AB INITIO METHOD AND EXPERIMENT
}

\author{
Appusamy Arunagiri ${ }^{1}$, Komal Priya ${ }^{2}$, Duraimurugan Alias Saravanan ${ }^{3}$, Ponnusamy Kalaichelvi ${ }^{4}$, \\ Ramalingam Anantharaj ${ }^{5}$ \\ ${ }^{1,2,3,4}$ Department of Chemical Engineering,National Institute of Technology Tiruchirappalli, \\ Tiruchirappalli, 620015Tamilnadu, India. \\ ${ }^{5}$ Department of Chemical Engineering, Faculty of Engineering, University of Malaya, \\ 50603Kuala Lumpur, Malaysia, anantharaj@um.edu.my
}

\begin{abstract}
It is critically important to understand the interactions between surfactant triton X-114 and reactive orange 107/water due to decolorization of waste water by surfactants. In this work, the structure of surfactant triton X-114, reactive orange 107 dyes, water, surfactant triton X-114+ reactive orange 107, surfactant triton X-114 + water and reactive orange 107dyes + water were optimized systematically at HF/6-31G level. It was found that reactive orange 107 is close to the surfactant triton X-114 structure. There exist $\mathrm{CH}-\mathrm{-} \pi$ interaction, $\pi--\pi$ interaction $n--H$ interaction and $n--\pi$ interactions between surfactant triton $X-114$ and reactive orange 107 dyes. The interaction energy between surfactant triton $X-114$ and reactive orange 107 dyes, water is $-92073.8853,4303.4720 \mathrm{~kJ} . \mathrm{mole}$ ${ }^{1}$, showing preferential adsorption of reactive orange 107 by surfactant triton X-114,in agreement with experimental results of surfactant triton $X-114$ + reactive orange 107 dyes in binary mixture at $303.15,313.15$ and $323.15 \mathrm{~K}$.
\end{abstract}

Keywords:Ab initio method, interaction energy, cloud point extraction, reactive orange 107dyes, triton X-114surfactant, thermodynamic properties

\section{INTRODUCTION}

Textile industries consume large amount of water and dyes for the wet processing of textiles, especially for coloring cotton, wool, silk and polyamide textiles. After wet processing, the colored effluents discharged from these industries are not found to be environmentally friendly and economically viable due to very low concentration of dyes present in these effluents. The presence of very low concentration of dyes in effluent discharged from these industries is highly visible and undesirable due to their chemical structure which causes higher thermal stability, low reactivity. In addition, dyes are highly resistant to fading when exposed to light, water, organic and inorganic solvents. Dyes have a synthetic origin and complex aromatic molecular structures and therefore it possess more stable and difficult to biodegradation, but it's highly soluble in water. Dyes have also been considered to be responsible for changing properties of waste water, and thus the waste water has high COD, large amount of suspended solids, largely fluctuating $\mathrm{pH}$,high temperature, unboundcolorants, dye impurities, auxiliaries and surfactants. Thus, they affect dyeing process efficiency, decolorization and degradedyeing waste water. Dyes in waste water have carcinogenic, mutagenic and bactericide properties [1-5].

According to the directive of ecological and toxicological association of dyes and organic pigments manufactures view, the removal of dyes from colored effluent is not an easy task but it is essential to protect the environment and minimize the teratogenic human health effect. On the other hand, the environmental protection agency proposed limit required less than $5 \mathrm{ppm}$ of dye content in waste water from 1500 p.m. by 2015 or near the future [6-8]. So far, various methods have been employed in wastewater treatment plant but they are inefficient for such depth removal of dyes. The various methods are adsorption, oxidation, coagulation, flocculation, chemical degradation, ozonation, enzymatic,catalyst, surfactant, photo degradation and combination of physiochemical and biological treatment. Therefore, the development of new technologies is of particular interest in providing environmentally friendly solution for dyes-free clean water. But it is a very serious challenge to the textile industry. 
Cloud point extraction (CPE) as an extraction method has been extensively used in the separation and purification process because of mild operating condition and very straightforward processes [9]. CAE process can be easily overcome the disadvantages of the above conventional method for decolorization of degradation of wastewater plants. At a certain temperature, aqueous solution of a nonionic surfactant becomes turbid. With further increase of temperature, solution separates into two phases such as surfactant rich phase and an aqueous phase.Surfactant rich phase has small volume compared to the solution and so- called coacervate phase, whereas the aqueous rich phase containing surfactant concentration slightly above the critical micelle concentration (CMC) [10]. This temperature is known as cloud point temperature (CPT) of the surfactant. The cloud point is strictly defined as a particular surfactant concentration (e.g., 1wt \%) due to phase boundary between two phases which is fairly independent of concentration. The cloud point is generally quite close to the lower consulate solution temperature. At the cloud point temperature, the solute present in aqueous solution of nonionic surfactant is distributed between two phases [11]. This phenomenon is known as cloud pointextraction (CPE) $[12,13]$.

The process efficiency depends on the surfactant types and chemical structure because there are several physical and chemical interactions involved in the formation of a complex between surfactant and dyes at a cloud point temperature [1416].On the other hand there is some possibility for structural orientation between similar aromatic ring structure of surfactant and dyes such as $\mathrm{CH}--\pi$ interaction, $\pi--\pi$ interaction, $n--\pi$ interaction [17-20]. Apart from these interactions, the charge -- charge interaction and hydrogen bond with neutral molecule interaction can also play important role in the separation of dyes from waste water [21]. In order to understand the reactivityof dyes with surfactant, the molecular identification of structure and hetero atom in the structure and their interaction energy are strongly needed to be clarified. But the molecular level analyses of dyes and surfactant have not been reported on elsewhere. It is well known that the thermodynamic properties could be explained very clearly about the interaction between two compounds such as excess molar volume [22] and deviation of refractive index, viscosity and surface tension [23-25].

Recently, ab initio molecular orbital calculation has become a powerful tool for studying intermolecular interactions and structural orientation. The intermolecular interaction and structural orientation can give detailed information about the ability, feasibility and efficiency of the process, in order to minimize the experimental cost and have chosen potential candidate for the particular separation process. Since the interactions energy control the structural assemblies and their properties in the mixture. Further, the removal of trace amount of reactive dyes from aqueous solution by current conventional method is not effective because of its chemical and physical resistant to the process. However the presence of heteroatoms in the aromatic structure of reactive orange 107, these species are involved in a great variety of chemical and physical interactions in the decolourization and recovery process using active absorbent, surfactant and catalyst. It is believed that a deep knowledge of these interactions can be of fundamental importance to understanding the intrinsic nature of the microscopic forces that regulate the phase equilibrium in waste water treatment.So far as we know, there are no published quantum chemistry studies on the interaction between complex formed between triton X-114 surfactant and reactive orange 107 dye and /or water molecules using $a b$ initio methods with $6-31 \mathrm{G}^{*}$ basis set.

The aim of the present work is to study the interaction energy of the complex formed between surfactant triton X-114 + water, surfactant triton $\mathrm{X}-114$ + reactive orange 107dyes and reactive orange 107 dyes + water system using ab initio methods with $6-31 \mathrm{G}^{*}$ basis set.To make the comparison and understand the behavior of interaction parameters in the above complex systems have been studied through cloud point extraction (CPA) process.Density, viscosity and refractive index of pure and mixture of surfactant triton $\mathrm{X}-114$, reactive orange 107 dyes and water were measured at 303.15, 313.15 and $323.15 \mathrm{~K}$. From the measureddata,the thermodynamic properties of these binary systems were calculated.It is very easy to understand the behavior of surfactant triton X-114 with reactive orange 107 dyes andwater molecules at different temperatures. In addition, the molecular aggregation in binary mixture can also be analyzed.

\section{COMPUTATIONAL DETAILS}

MOLDEN visualization package [26] has been used to prepare the chemical structure of triton X-114 surfactant (Figure 1), reactive orange 107 dyes(Figure 2) and water. The complex system of Triton $\mathrm{X}-114$ surfactant with reactive orange 107dyes (Figure 3), Triton X -114 surfactant with water molecules and reactive orange 107 with water molecules were drawn using dummy atom initially. After geometry optimization, the complex system does not have dummy atom which is making a barrier between these two molecules at gas phase studies. These similar concepts have been used earlier by Meng et. al. [27] and Turnet et.all,[28] for ab initio calculations.

Quantum chemical calculations were performed using Hartee Fock (HF) theory with $6-31 \mathrm{G}^{*}$ basis set. The geometry optimizations were carried out using HF/6-31G* level of theory. At the same level of theory, the fundamental vibrational frequency calculations were carried out to ensure the true minima. The total electronic energies for triton X-114 surfactant, reactive orange 107 dyes, water and their complex were corrected with the basis set superposition error using Boys-Bernardi counterpoise techniques [29]. All theoretical 
calculations were performed using the Gaussian03 software package [30].

\section{EXPERIMENTAL}

Triton X-114 surfactant, purchased from Sigma Life Sciences, India, was used as nonionic surfactant. It is highly pure and water-soluble liquid. Triton X-114 contains approximately 8 9 ethoxy units per molecule (density at $298.15 \mathrm{~K}$ is $1.058 \mathrm{~g}$. ml-1, Mol. Wt.: 537, $\lambda \max : 223 \mathrm{~nm}$ ), and is abbreviated as surfactant triton X-114 (Figure 1). The critical micelle concentration (CMC) of surfactant triton X-114 is $2.1 \times 10-4 \mathrm{M}$ at $298.15 \mathrm{~K}$ and cloud point temperature is $298.15 \mathrm{~K}[31]$. Reactive Orange 107dye (Mol.Wt:566.49, density: $1.7 \mathrm{~g} / \mathrm{ml}$, $\lambda \max : 411 \mathrm{~nm})$ purchased from Nuchem chemicals, Ahmedabad, India was used as solute (Figure 2). JASCO UVVis spectrophotometer was used for recording absorptionspectra and absorbance measurements using $1 \mathrm{~cm}$ glass cells and it was calibrated.The calibration curve for reactive orange 107 dyes is shown in Figure 4.

$50 \mathrm{ml}$ aqueous micellar solutions were prepared with different concentrations of solute and surfactant. The concentration of reactive orange dye used was $25 \mathrm{ppm}$. Surfactant triton X-114 concentration was varied from $0.01 \mathrm{M}$ to $0.1 \mathrm{M}$. In various literatures lower concentrations of surfactant were used, here we increased the concentration of surfactant up to $0.1 \mathrm{M}$ for more efficient results. Solutions were heated above CPT $(298.15 \mathrm{~K})$ at three different temperatures $303.15 \mathrm{~K}$, $313.15 \mathrm{~K}$, and $323.15 \mathrm{~K}$. The temperature above the cloud point temperatureof surfactant triton X-114 was taken for efficient cloud point extraction to take place. The solution separated into two phases above cloud point temperature. The volume of surfactant-rich phase and dilute phase were noted down. Then the concentration of reactive orange 107 dyes in dilute phase was determined by UV- Spectrophotometer.The viscosity of the separated phases was measured through Brookfield Viscometer LVDVII+PRO and the refractive index was measured by Deep Vision Refractometer(Guru Nanak Instruments, New Delhi). The refractometer was calibrated using water.For the measurement of density, $5 \mathrm{ml}$ specific gravity bottles were used.

\section{4 .RESULTS AND DISCUSSIONS}

The quantum chemical calculation and experiments were conducted using reactive orange 107 deys as a model anionic dye components and non-ionic surfactant triton-X 114. There are different kinds of interaction can exist between dye and surfactant / water molecules.It should be discussed in order to understand the physical, chemical and structural interaction. Dye solubilization results from the following interactions [32]:

- Dye is included into the polyoxyethylene exterior of micelles by hydrophilic interactions.

- Hydrophobic interactions result in absorption of dye into the hydrophobic core of surfactant micelles.
In non-ionic surfactants with the same hydrophobic group, as the ethylene oxide chain length decreases which cause micellize size increases whereasthe dye hydrophobicity decreases that cause solubilization tendency decreases.

The possible physical and chemical interaction between surfactant triton X-114 and reactive orange 107 dyes in the mixture such as van der Waals interactions between alkyl chains, hydrogen bond interaction with neutral molecules, charge-charge interaction, $\mathrm{n}(\mathrm{O}, \mathrm{N}, \mathrm{S})--\mathrm{H}$ interaction, $\mathrm{CH}-\pi$ interaction, $\pi--\pi$ interaction, $n(O, N, S)--\pi$ interactions [17-20].

There are certain interactions between water and surfactant molecules which affect the micellization of surfactant molecules and solubilizaton of dye [33].

(i) Steric and electrostatic interactions between surfactant hydrophilic moieties and water,

(ii) Conformational effects associated with hydrocarbonchain packing in the micellar core,

(iii) Curvature-dependent interfacial effects at the micellar core-water interface, and

(iv) Hydrophobic interactions between surfactant hydrocarbon chains and water.

\subsection{Structure and Interaction Energy}

Reactive orange 107 dyes are having two aromatic rings and several functional groups. The functional group in reactive orange 107 dyes is classified into two categories such as chromofore and auxochromoe. The chromofore configurations are represented by the azo group $(-\mathrm{N}=\mathrm{N}-)$, ethylene group $(=\mathrm{C}=\mathrm{C}=)$, methine group $(-\mathrm{CH}=)$, carbonyl group $(=\mathrm{C}=\mathrm{O})$, carbon-nitrogen $(=\mathrm{C}=\mathrm{NH})$, carbon-sulfur $(=\mathrm{C}=\mathrm{S})$, Nitro $(-$ $\mathrm{NO} 2 ;-\mathrm{NO}-\mathrm{OH})$, nitrozo $(-\mathrm{N}=\mathrm{O} ;=\mathrm{N}-\mathrm{OH})$. These groups are having highly electron acceptor which is indicating that the groups of molecule looking for a rich electron center of the atom in the chemical structure whereas the color of individual dye is strongly depends on the presence of chromogenechromophore groups in their structures. Therefore, the reactive orange 107 has a golden yellow color. The auxochrome groups are ionizable groups which are responsible for the dyeing capacity in the textile material and other materials. The usual auxochrome groups are amines (-NH2), carboxyl ($\mathrm{COOH})$, sulphonate $(-\mathrm{SO} 3 \mathrm{H})$, and hydroxyl $(-\mathrm{OH})$. These groups of molecules are having electron deficiency of the atom in their molecular structure. Thus, the group of molecules is existing low reactivity and high thermal and chemical stability to deep conventional process such as adsorption, precipitation, chemical degradation, photo degradation, etc. The optimized structure of surfactant triton $\mathrm{X}-114$, reactive orange 107 dyes and surfactant triton X-114+ reactive orange 107 is given in Figure 1 to Figure 3.

The surfactant triton $\mathrm{X}-114$ is consisting of the aromatic ring, carbon, and hydrogen and oxygen atom in their chemical structure. The total hydrogen atom in the surfactant triton X- 
114 is 50 which is higher than reactive orange 107 dyes whereas the electronegative atom and ions such as nitrogen, oxygen, sulfuratom and sodium ions located in the reactive orange is 19 (4 nitrogen, 3 sulfur, 10 oxygen and 2 sodium ions) which cause the rate of decolourization, degradability and recovery of dyes from aqueous solution. However, these electronegative atom and ions are playing significant role in the formation of a bond between active surfactant, namely, triton X-114 and reactive orange 107 dyes. Further, there are several possible electron donor sites as available in the surfactant to have hydrogen interaction with the neighboring molecules like reactive orange 107 dyes. Furthermore the surfactant triton X-114 and reactive orange 107 dyesare having similar aromatic ring structure at the center of their structures.It can be influenced on the effective structural orientation between those two similar molecules via $\pi--\pi$ stacking and $\mathrm{CH}--\pi$ interaction and no $(\mathrm{N}, \mathrm{S}, \mathrm{O})--\pi$ interaction [17-20].

The total electronic energy of surfactant triton X-114, reactive orange 107 dyes, water and their complex structures have been studied using ab initio method and the results are presented in Table 1.The total electronic energy of reactive orange is 8131907.327 kJ.mole-1 (Table 1) whereas the surfactant has 2022439.464 kJ.mole-1 (Table 1) and -199505.7064 kJ.mole-1 (Table 1) for water molecules. The total electronic energy of surfactant triton X-114 is less than reactive orange 107 dyes whereas higher than that of water molecules. It can be explained that the removal of reactive orange 107 dyes from water molecules required higher degree of adsorbent or catalyst than that of reactive orange 107 dyes. The reactive orange 107 dyes have more electron deficiency of atom located in their molecular structure as well as unsaturated bond orderwhich cause reactivity and stability of the molecules in the complex systems.

From the total electronic energy values of individual molecules such as reactive orange 107 dyes, surfactant triton $\mathrm{X}-114$, water, surfactant triton X-114+reactive orange 107 dyes, surfactant triton X-114+ water and reactive orange 107 dyes + water have been calculated and it's given in Table 1 . The interaction energy of the complex system can be defined as the difference between the total electronic energy of mixture and total electronic energy of individual molecules which can give the information about the strength of hydrogen bond formation between two or more compounds in the mixture. The interaction energy can be calculated according to the following equation 1,2 and 3.

$$
\begin{gathered}
I E_{\text {Surfactan } t-\text { Dyes }}=T E_{\text {Surfact } \operatorname{an} t+\text { Dyes }}-\left(T E_{\text {Surfac } \tan t}+T E_{\text {Dyes }}\right) \\
I E_{\text {Surfactan } t-\text { Water }}=T E_{\text {Surfact an } t+\text { Water }}-\left(T E_{\text {Surfac } \tan t}+T E_{\text {Water }}\right)
\end{gathered}
$$

$$
I E_{\text {Dyes-Water }}=T E_{\text {Dyes+Water }}-\left(T E_{\text {Dyes }}+T E_{\text {Water }}\right)
$$

Where, IE and TE are the interaction energy and total electronic energy of the molecules and their cluster. The interaction energy of the complex formed between surfactant triton X-114 and reactive orange 107 dyes have 92073.8853kJ.mole-1 (Table 1) whereas 4303.4720 kJ.mole-1 (Table 1) for surfactant triton X-114 + water, 4203.10926kJ.mole-1 (Table 1) for reactive orange 107 dyes + water systems. The interaction energy between surfactant triton X-114 + reactive orange 107 dyes show smaller values with negative sign than that of reactive orange 107 dyes +water and surfactant triton X-114+water systems due to the presence of appreciable level of physical, chemical and structural interaction between surfactant and dyes. It is observed that surfactant triton $\mathrm{X}-114$ has high potential to separate reactive orange 107 dyes from aqueous solution because these two molecules have several possible physical, chemical and structural interactions such asCH-- $\pi$ interaction, $\pi--\pi$ interaction, $n(S, N, O)--\pi$ interaction , S--H interaction, $\mathrm{N}-\mathrm{-H}$ interaction, $\mathrm{O}-\mathrm{-H}$ interaction, hydrogen bond interaction with neutral molecules and charge--charge interaction[17-20]. Further, the charge--charge interaction is the dominant interaction in the attraction and that the interaction of surfactant triton X-114 with reactive orange 107 dyescomplex have smallervalues than that of surfactant triton X-114 + water complex and reactive orange 107 dyes + water. The surfactant triton X-114 is not close to water molecules, resulting in immiscible with each other. It can be easily observed that the interaction energy is inversely proportional to distance between two interacting molecules. However the conventional hydrogen bonds have strong directionality and therefore, hydrogen bonds play important roles in controlling the structure of molecular assemblies and their properties.

\subsection{Effect of Surfactant Concentration and}

\section{Temperature on Refractive Index}

Refractive index is related to the polarizability of molecules in binary mixture. They can provide clear information aboutthe interactionbetween those two molecules.In order to study the effect of interactions with increasing alkyl chain length, the refractive index of pure and mixture were measured (Table 2). It was noted that there is chemical resistance offered which cause familiar physical and chemical interactions [34] due to the deficiency of the hydrogen atom.Figure 5 shows the variation of refractive index with surfactant concentration 0.01 $\mathrm{M}$ to $0.1 \mathrm{M}$ intwo differentphases. For aqueous phase, refractive index is constant with increasing surfactant concentration at $25 \mathrm{ppm}$ of dye concentration. The aqueous phase mainly consists of water, whereas dye and surfactant are present in negligible amount. The aqueous phase has the same refractive index of water at room temperature i.e. 1.332 with increasing surfactant concentration. The constituents of 
coacervate phase are same as aqueous phase but the presentof water is in negligible. In Figure 5, the refractive index increases with surfactant concentration. The increase in surfactant concentration causes more solubilization of dye which increases the dye concentration in the coacervate phase. This shows the refractive index of the phase is dependent upon the composition of the phase and the amount of constituent present.

The refractive index of the aqueous phase is same as water 1.332 , even at different temperatures (Table 2). It is noted that the amount of water influences on the refractive index of the aqueous phase as well as the concentration of the dye and surfactant has negligible. The refractive index is increased with the increase in temperature (Table 2). As temperature increases, the CMC value of surfactant decreases and that causes increased dye solubilization. Water molecules are dehydrated with increase in temperature in the coacervate phase. Polar interaction between water and surfactant molecule decreases whereas the hydrophobic interaction of surfactant with dye increases with increase in temperature. Due to decrease in the amount of water and increase in the amount of dye in coacervate phase the refractive index increases (Table 2). Thus, the refractive index of binary mixture depends on the amount of dye and water present in the coacervate phase.

\subsection{Effect of Surfactant Concentration and}

\section{Temperature on Density}

Reactive Orange is an anionic dye. The density of the mixtures is very strongly affected by the nature of the anion. Density is related to the compactness of the structure of molecules. The density in dilute phase is almost constantly with the increase in surfactant concentration (Table 3) whereas the coacervate phase density increases with increase in surfactant concentration due to the presence of physical and chemical interaction. Reactive orange 107 dyesare present more in coacervate phase than dilute phase. Therefore there is a big difference in the values of the density of dilute and coacervate phase and also to increase in surfactant concentration.Density of dilute phase decreases with increase in temperature due to the presence of water and thus reduces the strength of hydrogen in the mixture (Table 3). At lower concentrations of surfactant, there is not much effect of temperature but as surfactant concentration increases the density decreases with increase in temperature (Table 3). This can be explained that thehydrogen bonding is more temperature dependent than compositions. At lower temperature, there is more hydrogen bonding interaction between water and surfactant molecules but at higher temperatures there is a dissociation of water molecules from the surfactant molecules. So, the amount of water increases in dilute phase of higher surfactant concentration therefore resulting in a decrease in density.Density of coacervate phase increases with increase in temperature. For temperature 303 and $323 \mathrm{~K}$ there is gradual increase in density with increase in surfactant concentration but for $313 \mathrm{~K}$ there is a rapid increase in density in surfactant concentration (Table 3). The density of coacervate phase increases with temperature because there is a dehydration of water molecules from surfactant molecules present in coacervate phase. The decrease in water content with temperature causes the density to increase with temperature.

\subsection{Effect of Surfactant Concentration and}

\section{Temperature on Viscosity}

Viscosity is an important parameter in molecular interaction studies. It has a strong effect on the rate of mass transport within the solution. The viscosity of water is $0.8903 \mathrm{CP}$ at 298 $\mathrm{K}$. The identities of the anion and the cation which composes the mixture have a huge effect on the viscosity of the liquid mixture. Viscosity is also affected by the Van der Waals force interaction. The interaction increases with ions exhibiting long alkyl chains or a higher degree of branching. With respect to the anionic species, higher basicity, size and relative capacity to form $\mathrm{H}$-bonds leads to more viscous mixtures. The viscosity is almost constant with an increase in surfactant concentration for dilute phase (Table 4). There is much amount of water present in dilute phase so the viscosity of dilute phase lies around that of water.

The viscosity increases with increase in surfactant concentration in coacervate phase (Table 4). This is due to the anionic nature of more dye solubilized with increasing surfactant concentration. With the increase in surfactant concentration, micelle concentration also increases due to which more dye is solubilized. As the more dye is solubilized in surfactant, van der wall interaction between dye and surfactant increases. As already mentioned viscosity is affected by increased van der Waal interaction therefore viscosity is increased.There is no significant variation with temperature in coacertvate phase (Table 4). The viscosity of dilute phase is almost in between 0.75 and $0.89 \mathrm{mPa} . \mathrm{S}-1$. This shows that the viscosity of dilute phase is depended strongly on water content and weakly on temperature. The viscosity increases with increase in temperature and decreases with water content. As temperature is increased the dehydration of surfactant molecules results in decreased content of water in coacervate phase. As content of water decreases with temperature the viscosity of the coacervate phase increases as it leads to more solubilization of dye with increasing temperature. With increase in temperature hydrophobicity of surfactant molecules increases which leads to more interaction of dye with the hydrophobic part. Water interacts with the hydrophilic part of TX-114 through dipoledipole interactions. As temperature increases hydrophilic nature of surfactant is reduced which results in dehydration of water molecules. A small quantity of water causes a great viscosity decrease. Thus this figure shows the great variations of viscosity depend on the water content at all the studied temperature (Table 4). 


\subsection{Effect of Temperature and Concentration on}

\section{Excess Molar Volume (VE)}

The excess molar volume depends on the composition and temperature and is of great importance in understanding the nature of molecular aggregation that exists in the mixture. The excess molar volume is calculated by the following formula:

$$
\mathrm{V}_{\mathrm{E}}=\sum_{\mathrm{i}=1}^{3} \frac{\mathrm{x}_{\mathrm{i}} \mathrm{M}_{\mathrm{i}}}{\rho_{\text {mix }}}-\sum_{\mathrm{i}=1}^{3} \frac{\mathrm{x}_{\mathrm{i}} \mathrm{M}_{\mathrm{i}}}{\rho_{\mathrm{i}}}
$$

Where $x i(i=1,2,3)$ is the mole fractions of dye (Reactive Orange), surfactant (TX-114) and water respectively. Mi, (i $=1,2,3)$ is the molecular weights of dye, surfactant and water respectively. $\square \mathrm{i}(\mathrm{i}=1,2,3)$ is the density of the mixture (dye + surfactant +water).

VE is the result of contribution from several opposing effects which is divided into three types - physical, chemical and structural effect [29]. Physical effects are due to non-specific physical interactions such as dispersion force due to breaking of dipoles or weak dipole-dipole interaction and van der Waals interaction between alkyl chains. Chemical effect includes charge - charge interaction, H-bond interaction, and donoracceptor complex forming interactions, $\mathrm{CH}--\pi$ interaction, $\pi--\pi$ interaction $\mathrm{n}(\mathrm{O}, \mathrm{S}, \mathrm{N})--\mathrm{H}$ interaction and $\mathrm{n}(\mathrm{S}, \mathrm{O}, \mathrm{N})--\pi$ interaction [17-20].Structural effect isgeometrical fitting of the component molecules into each other's structure and due to the difference in molar and three volumes.Physical effects make a positive contribution to $\mathrm{VE}$, chemical and structural effects make a negative contribution. Negative VE values indicate that the chemical contributions are dominant. The chemical or specific intermolecular interactions result in a volume decrease, and these include charge transfer type forces and other complex forming interactions. The structural contributions are mostly negative and arise especially from interstitial accommodation and changes of free volume. Values of VE nearly zero, implies that the interactions between unlike molecules are very similar to the intramolecular interactions.

Figure 6 implies that the negative values of excess molar volume are due to the dominant chemical effects than the other effects in cloud point extraction. VEdecreases with increase in temperature and surfactant concentration. At higher temperature the chemical effects decreases and the interaction between the like and unlike molecules are almost similar i.e VE approaches zero, so there is very less interaction between dye and surfactant and extraction of dye is inefficient. So up to a certain value of temperature there is an effective extraction of dye by surfactant and above a certain temperature solubilization of dye decreases. As surfactant concentration is increasing there is increase in excess molar volume which shows increasing chemical and structural effect with increasing surfactant concentration. So, the more dye is solubilized with increasing surfactant concentration (Table 5).

\section{CONCLUSIONS}

A systematic study on the relative surfactant triton X-114, reactive orange 107 dyes, water and its cluster total electronic energy and thereby interaction energy for complex formed betweensurfactant triton X-114+reactive orange 107 dyes, surfactant triton $\mathrm{X}-114+$ reactive orange 107 and reactive orange $107+$ water were performed in this work using ab initio methods with $6-31 G^{*}$ basis set. The results on the complex systems relative interaction were interpreted in terms of influence of structure of both surfactant triton X-114 and reactive orange 107 dyes, deficiency of hydrogen atom in the reactive orange 107 dyes, the presence of electronegative atom in the aromatic structure of reactive orange 107 dyes and some other phytochemical interactions such as charge - charge interaction, H-bond interaction, and donor-acceptor complex forming interactions, van der Waals interaction between alkyl chain, $\mathrm{CH}--\pi$ interaction, $\pi--\pi$ interaction $\mathrm{n}(\mathrm{O}, \mathrm{S}, \mathrm{N})--\mathrm{H}$ interaction and $n(S, O, N)--\pi$ interaction. To identify the possible molecular interaction in the mixture of the above systems experiment was carried out at different temperature and different concentration of surfactant.In order to measure the density, refractive index and viscosity of pure and mixedat $303.15,313.15$ and $323.15 \mathrm{~K}$ and calculated their excess molar properties. There is no significant concentration effect in dilute phase of mixture properties whereas in coacervate phase shows reliable influenced by the concentration of surfactant. It is noted that density is strongly depends on temperature as well as concentration of surfactant and the viscosity is dependent on water or moisture content than temperature. It is also observed that the surfactant triton $\mathrm{X}-114$ and reactive orange 107 dyes have mutual molecular interaction and therefore they exhibit negative deviations while increasing temperature the deviation has been changed drastically due to minimize the effect of hydrogen bonds in the mixture. Moreover, itis concluded that there is a strong possibility toremovetraces of dyes from aqueous solution without additional equipment requirements. But the structure assemblies and their propertyrelationships are essential factors to enhance the process efficiency.

\section{NOMENCLATURE}

\begin{tabular}{|l|l|}
\hline CPE & Cloud point extraction \\
\hline IE & Interaction energy \\
\hline TE & Total electronic energy \\
\hline xi & Mole fraction of component $\mathrm{i}$ \\
\hline $\mathrm{Mi}$ & Molecular weight of component $\mathrm{i}$ \\
\hline $\boldsymbol{\rho} \mathrm{i}$ & Density of component $\mathrm{i}$ \\
\hline $\boldsymbol{\rho}$ mix & Density of mixture \\
\hline VE & Excess molar volume \\
\hline
\end{tabular}




\section{ACKNOWLEDGEMENTS}

The work is partially supported by Tamil Nadu State Council for Science and Technology (TNSCST/S\&T project/VR/ES/2009-2010). The authors wish to thank Taminadu State Council Science and Technology for their financial support.

\section{REFERENCES}

[1]. Won, S.W., Choi, S.B., Yun, Y.: Performance and mechanism in binding of ReactiveOrange 16 to various types of sludge. Bioch. Eng. Journal. 28,208-214 (2006)

[2]. Renganathan, S., Thilagaraj, W.R., Miranda, L.M.,Gautam, P. , Velan, M.: Accumulation of Acid Orange 7, Acid Red 18 and Reactive Black 5 by growing Schizophyllum commune. Biore.Technology. 97,2189-2193(2006)

[3]. Greluk, M., Hubicki, Z.: Comparison of the gel anion exchangers for removal of Acid Orange 7 from aqueous solution, Chem. Engg. Journal 170,184193(2011)

[4]. Tizaoui, C., Grima, N.: Kinetics of the ozone oxidation of Reactive Orange 16 azo-dye in aqueous solution. Chem.Engg. Journal 173, 463- 473(2011)

[5]. Rio ,A., Molina, J., Bonastre, J., Cases, F.: Influence of electrochemical reduction and oxidation processes on the decolourisation and degradation of C.I.

Reactive Orange 4 solutions. Chemosphere. 75 13291337 (2009)

[6]. Aksu, Z.C., Cagatay, S.S.: Investigation of biosorption of Gemazol Turquoise Blue-G reactive dye by dried Rhizopus arrhizus in batch and continuous systems. Sepa.and Puri. Technology.48,24-35(2006)

[7]. Lata, H.,Garg, V.K., Gupta, R.K.: Removal of a Basic Dye from Aqueous Solution by Adsorption Using Parthenium Hysterophorus: An Agricultural Waste. Dyes and pigments.74, 653-658(2007)

[8]. Purkait,M.K., Das Gupta,S., De,S.: Determination of design parameters for the Cloud Point Extraction of Congo red and eosin dyes using Triton X-100. Sepa. Sci. $\quad$ and Technology.51,137-142(2006)

[9]. Gullickson, N.D., Scamehorn, J.F., Harwell,J.H.:Liquid-coacervate extraction. In Scamehorn, J.F., Harwell,J.H. (Eds.), Surfactant Based Separation Processes. MarcelDekker Inc., New York, 139-152(1989)

[10]. Kimchuwanit,W., Osuwan, S., Scamehorn, J.F., Harwell, J.H.,Haller, K.J.: Use of a micellar-rich coacervate phaseto extract trichloroethylene from water. Sepa.Sci. and. Technology.35 , 1991-2002 (2000)

[11]. Wang, Z., Zhao, F., Li, D.: Determination of solubilizationof phenol at coacervate phase of cloud point extraction.Colloid. Surf. A: Physico. Eng. Aspects.216,207-214(2003)
[12]. Purkait, M.K., Vijay, S.S., Dasgupta,S., De, S.: Separation of Congo red by surfactant mediated cloud point extraction. Dyes Pigments.63,151-159(2004)

[13]. Purkait, M. K., Banerjee, S., Dasgupta,S., De, S.:Cloud point extraction of toxic eosin dye using Triton X-100 as nonionic surfactant. Water Res.39, 3885-3890(2005)

[14]. Dutta,R.K., Bhat,S.N.: Dye-Surfactant Interaction in Submicellar Concentration Range, Bullet.Chem.Soc. Japan.65,1089-1095(1992)

[15]. Simoncic, B., Span, J.: A Study of Dye-Surfactant Interactions. Part 1. Effect of Chemical Structure of Acid Dyes and Surfactants on the Complex Formation.Dyes and Pigments.36, 1-14(1998)

[16]. Simoncic, B., Kovac, F.: A Study of Dye-Surfactant Interactions. Part 2. The Effect of Purity of a Commercial Cationic Azo Dye on Dye-Surfactant Complex Formation.Dyes and Pigments.40,1-9(1991)

[17]. Fernandes, A.M., Rocha, M.A.A., Freire, M.G., Marrucho ,I.M., Coutinho ,J.A.P., Santos, M.N.B.F.: Evaluation of Cation-Anion Interaction Strength in Ionic Liquids. J.Phy. Chemistry B 2011; 115: 40334041.

[18]. Lu, R., Lin, J., Qu, Z.:Theoretical study on interactions between thiophene/dibenzothiophene/cyclohexane/toluene and 1-methyl-3-octylimidazolium tetrafluoroborate.Stru.Chemistr DOI 10.1007/s11224012-0106-z.

[19]. Castellano, O., Gimon, R., Soscun, H.: Theoretical Study of the $\sigma-\pi$ and $\pi-\pi$ Interactions in heteroaromaticmonocyclic Molecular Complexes of Benzene, Pyridine, and Thiophene Dimers: Implications on the Resin-Asphaltene Stability in Crude Oil. Energy \&Fuels. 25,2526-2541(2011)

[20]. Anantharaj, R., Banerjee, T.: Quantum chemical studies on the simultaneous interaction of thiophene and pyridine with ionic liquid. AIChE Journal .57,749764(2011)

[21]. Manian, A.P.: Dye-Surfactant Interactions in Thermosol Dyeing, approved by University of Georgia, Aug 2002.

[22]. Yadava, S.S., Yadav, A.P.: Ultrasonic behavior of binary liquid mixtures of 1-bromopropane with cyclohexane and benzene. Ind. J.Pure \& App.Physics.42,338-340 (2004)

[23]. Saravanakumar, K., Baskaran, R., Kubendran, T.R.:Densities, Viscosities, Refractive Indices and Sound Speeds of Acetophenone with Methylacetate at Different Temperatures. J.Chemistry.9,17111720(2012)

[24]. Doroschuk, V.O., Kulichenko, S.A.,Lelyushok, S.O.: The influence of substrate charge and molecular structure on interphase transfer in cloud point extraction systems. J.Coll. and Inter. Science.291,251-255(2005)

[25]. Yanfang,G., Tengfang, W., Dahong, Y., Changjun, P., Honglai,L., Ying, H.: Densities and Viscosities of the 
Ionic Liquid $[\mathrm{C} 4 \mathrm{mim}][\mathrm{PF} 6]^{+} N, N$-dimethylformamide Binary Mixtures at $293.15 \mathrm{~K}$ to $318.15 \mathrm{~K}$. Chin. J. Chem.l Engineering.16,256-262 (2008)

[26]. Schaftenaar, G., Noordik, J.H.: Molden: a pre- and post-processing program for molecular and electronic structures. J.Comp. Aid. Mole. Design. 14,123134(2000)

[27]. Meng, J., Dolle, A., Carper, R.W.: Gas phase model of an ionic liquid: Semi-empirical and ab-initio bonding and molecular structrure.J. Mole.Structure (Theo).585,119-128(2002)

[28]. Turner, E.A., Pye, C., Singer, R.D.: Use of ab-initio calculations toward the rational design of room temperature ionic liquids. J.Phys. Chemistry A.107,2277-2288(2003)

[29]. Boys,S., Bernardi, F.: Mole. Physics. 19,553(1970)

[30]. Frisch, M. J., Trucks, G.W.,Schlegel, H.B., Scuseria, G. E.,Robb, M.A., Cheeseman, J.R., Montgomery ,J. A., Vreven. T., Kudin,K.N., Burant, J.C., Millam, J.M., Iyengar, S.S., Tomasi,J.,Barone, V., Mennucci, B., Cossi, M., Scalmani,G., Rega,N., Petersson,G. A., Nakatsuji, H., Hada. M., Ehara, M., Toyota, K.,Fukuda.R., Hasegawa. J., Ishida, M.,Nakajima, T.,Honda, Y., Kitao, O., Nakai, H., Klene, M., Li, X., Knox, J.E., Hratchian, H.P., Cross, J.B., Bakken, V.,Adamo, C., Jaramillo, J., Gomperts, R., Stratmann, R.E., Yazyev, O., Austin, A.J., Cammi, R., Pomelli, C., Ochterski, J. W., Ayala ,P.Y.,Morokuma. K., Voth, G.A., Salvador, P., Dannenberg, J.J., Zakrzewski,V.G.,

Dapprich, S., Daniels, A.D., Strain, M.C,, Farkas, O., Malick,D.K., Rabuck, A.D., Raghavachari,K.,

Foresman, J.B,, Ortiz,J.V., Cui,Q., BaboulA.G., Clifford, S., Cioslowski, J.,Stefanov,B. B., Liu, G, Liashenko, A., Piskorz,P., Komaromi, I., Martin, R.L., Fox, D.J., Keith,T., Al-Laham,M .A., Peng, C.Y., Nanayakkara, A., Challacombe, M., Gill, P.M.W.,Johnson, B., Chen,W., Wong,M.W., Gonzalez,C., Pople, J.A.: Gaussian 03, Revision C.02; Gaussian: Pittsburgh, PA, 2004.

[31]. Musnickas, J., Skulkina, O., Treigiene, R., Rageliene, L.: Effect of the Interaction between Acid Dye and Nonionic Surfactants on the Adsorption of Dye in Wool Fibre, Fibres \& Textiles in Eastern Europe.16,70(2008)

[32]. Puvvada.: Molecular thermodynamic approach to predict micellization, phase behavior and phase separation of micellar solutions.Mass. Inst.Technology.1-15(1989)

[33]. Yadava, S. S., Yadav, A., Kushwaha,N,, Yadav, N.: Refractometric studies on molecular interactions between some bromoalkanes and nonpolar hydrocarbons. Ind.J.chemistry .48,650-657(2009)

[34]. Gowrisankar, M., Sivarambabu, S., Venkateswarlu, P., Siva Kumar, K.: Excess Volumes, Speeds of Sound, Isentropic Compressibilities and Viscosities of Binary Mixtures of N-Ethyl Aniline with Some Aromatic Ketones at 303.15 K. Bull. Korean Chem. Soc.5,33 (2012)

Table1: The total electronic energy and Interaction energies between triton X-114, reactive orange 107 and their complex using ab initio method with $6-31 \mathrm{G}^{*}$ basis set.

\begin{tabular}{|l|l|c|c|}
\hline S.No & \multicolumn{1}{|c|}{ Name } & $\begin{array}{c}\text { Total energy } \\
(\mathbf{k J . m o l e})^{-1}\end{array}$ & $\begin{array}{c}\text { Interaction energy } \\
\left(\mathbf{k J . m o l e} \mathbf{e}^{-1}\right)\end{array}$ \\
\hline 1 & $\begin{array}{l}\text { Dyes: } \\
\text { Reactive orange 107 (RO107) }\end{array}$ & -8131907.327 & - \\
\hline 2 & $\begin{array}{l}\text { Surfactant: } \\
\text { Triton X-114 (TX-114) }\end{array}$ & -2022439.464 & - \\
\hline 3 & Water & -199505.7064 & - \\
\hline 4 & RO107+Water & -8327209.924 & 4203.109259 \\
\hline 5 & TX-114+Water & -2217641.698 & 4303.472023 \\
\hline 6 & TX-114+RO107 & -10246420.68 & -92073.88529 \\
\hline
\end{tabular}


Table 2: Experimental Refractive index values for dilute and coacervate phase as a function of temperature and surfactant concentration.

\begin{tabular}{|c|c|c|c|c|c|c|}
\hline \multirow{2}{*}{\begin{tabular}{l} 
Surfactant $\begin{array}{l}\text { Concentration } \\
(\mathbf{M})\end{array}$ \\
\cline { 2 - 7 }
\end{tabular}} & \multicolumn{2}{|c|}{$\mathbf{3 0 3 . 1 5 K}$} & \multicolumn{2}{|c|}{$\mathbf{3 1 3 . 1 5 K}$} & \multicolumn{2}{c|}{ 323.15K } \\
\cline { 2 - 7 } & Dilute & Coacervate & Dilute & Coacervate & Dilute & Coacervate \\
\hline 0.01 & 1.332 & 1.3580 & 1.332 & 1.3605 & 1.332 & 1.3530 \\
\hline 0.02 & 1.332 & 1.3560 & 1.332 & 1.3630 & 1.332 & 1.3560 \\
\hline 0.03 & 1.332 & 1.3585 & 1.332 & 1.3640 & 1.332 & 1.3588 \\
\hline 0.04 & 1.332 & 1.3595 & 1.332 & 1.3660 & 1.332 & 1.3610 \\
\hline 0.05 & 1.332 & 1.3610 & 1.332 & 1.3665 & 1.332 & 1.3625 \\
\hline 0.06 & 1.332 & 1.3610 & 1.332 & 1.3690 & 1.332 & 1.3670 \\
\hline 0.07 & 1.332 & 1.3680 & 1.332 & 1.3685 & 1.332 & 1.3695 \\
\hline 0.08 & 1.332 & 1.3680 & 1.332 & 1.3695 & 1.332 & 1.3745 \\
\hline 0.09 & 1.332 & 1.3610 & 1.332 & 1.3700 & 1.332 & 1.3750 \\
\hline 0.1 & 1.332 & 1.3610 & 1.332 & 1.3710 & 1.332 & 1.3780 \\
\hline
\end{tabular}

Table 3: Experimental Density values in $\mathrm{g} / \mathrm{cc}$ for dilute and coacervate phase as a function of temperature and surfactant concentration.

\begin{tabular}{|c|c|c|c|c|c|c|}
\hline \multirow{2}{*}{\begin{tabular}{l} 
Surfactant $\begin{array}{l}\text { Concentration } \\
\text { M) }\end{array}$ \\
\cline { 2 - 7 }
\end{tabular}} & \multicolumn{2}{|c|}{$\mathbf{3 0 3 . 1 5}$} & \multicolumn{2}{c|}{ 313.15 } & \multicolumn{2}{c|}{ 323.15 } \\
\cline { 2 - 7 } & Dilute & Coacervate & Dilute & Coacervate & Dilute & Coacervate \\
\hline 0.01 & 1.000032 & - & 1.000030 & - & 1.000022 & - \\
\hline 0.02 & 1.000073 & - & 1.000142 & - & 1.000037 & - \\
\hline 0.03 & 1.000163 & - & 1.000196 & - & 1.000000 & - \\
\hline 0.04 & 1.000254 & - & 1.000175 & - & 1.000251 & - \\
\hline 0.05 & 1.000456 & 1.013099 & 1.000182 & - & 1.000222 & - \\
\hline 0.06 & 1.000417 & 1.014066 & 1.000222 & 1.012756 & 1.000235 & 1.017372 \\
\hline 0.07 & 1.000472 & 1.014194 & 1.000378 & 1.015736 & 1.000273 & 1.017889 \\
\hline 0.08 & 1.000636 & 1.013592 & 1.000449 & 1.018362 & 1.000354 & 1.019479 \\
\hline 0.09 & 1.000626 & 1.014833 & 1.000525 & 1.019535 & 1.000317 & 1.019904 \\
\hline 0.1 & 1.000707 & 1.015070 & 1.000527 & 1.020131 & 1.000396 & 1.019183 \\
\hline
\end{tabular}


Table 4: Experimental Viscosity values in $\mathrm{mPa} / \mathrm{s}$ for dilute and coacervate phase as a function of temperature and surfactant concentration.

\begin{tabular}{|c|c|c|c|c|c|c|}
\hline \multirow{2}{*}{\begin{tabular}{l} 
Surfactant $\begin{array}{l}\text { Concentration } \\
(\mathbf{M})\end{array}$ \\
\cline { 2 - 7 }
\end{tabular}} & \multicolumn{2}{|c|}{$\mathbf{3 0 3 . 1 5}$} & \multicolumn{2}{|c|}{$\mathbf{3 1 3 . 1 5}$} & \multicolumn{2}{c|}{$\mathbf{3 2 3 . 1 5}$} \\
\cline { 2 - 7 } & Dilute & Coacervate & Dilute & Coacervate & Dilute & Coacervate \\
\hline 0.01 & 0.74 & - & 0.820 & - & 0.840 & - \\
\hline 0.02 & 0.74 & - & 0.820 & - & 0.860 & - \\
\hline 0.03 & 0.7 & - & 0.820 & - & 0.860 & - \\
\hline 0.04 & 0.74 & - & 0.840 & - & 0.860 & - \\
\hline 0.05 & 0.8 & - & 0.840 & - & 0.880 & - \\
\hline 0.06 & 0.78 & 122.7 & 0.840 & - & 0.880 & 155.700 \\
\hline 0.07 & 0.82 & 123.9 & 0.860 & 135.900 & 0.880 & 173.600 \\
\hline 0.08 & 0.84 & 126.9 & 0.860 & 148.800 & 0.900 & 181.800 \\
\hline 0.09 & 0.84 & 127.9 & 0.860 & 161.100 & 0.900 & 174.600 \\
\hline 0.1 & 0.84 & 129.8 & 0.880 & 161.100 & 0.900 & 171.900 \\
\hline
\end{tabular}

Table 5: Experimental Excess molar values in $\mathrm{mPa} / \mathrm{s}$ for dilute and coacervate phase as a function of temperature and surfactant concentration.

\begin{tabular}{|c|c|c|c|}
\hline \multirow{2}{*}{$\begin{array}{c}\text { Surfactant } \\
\text { Concentration(M) }\end{array}$} & \multicolumn{3}{|c|}{ Temperature (K) } \\
\cline { 2 - 4 } & $\mathbf{3 0 3 . 1 5}$ & $\mathbf{3 1 3 . 1 5}$ & $\mathbf{3 2 3 . 1 5}$ \\
\hline 0.01 & -0.00057 & -0.00054 & -0.00038 \\
\hline 0.02 & -0.00129 & -0.00254 & -0.00066 \\
\hline 0.03 & -0.00292 & -0.00351 & 0.00456 \\
\hline 0.04 & -0.00456 & -0.00314 & -0.00450 \\
\hline 0.05 & -0.00476 & -0.00476 & -0.00398 \\
\hline 0.06 & -0.00749 & -0.00398 & -0.00422 \\
\hline 0.07 & -0.00628 & -0.00628 & -0.00491 \\
\hline 0.08 & -0.01143 & -0.00807 & -0.00637 \\
\hline 0.09 & -0.01126 & -0.00943 & -0.00570 \\
\hline 0.1 & -0.01271 & -0.00947 & -0.00711 \\
\hline
\end{tabular}




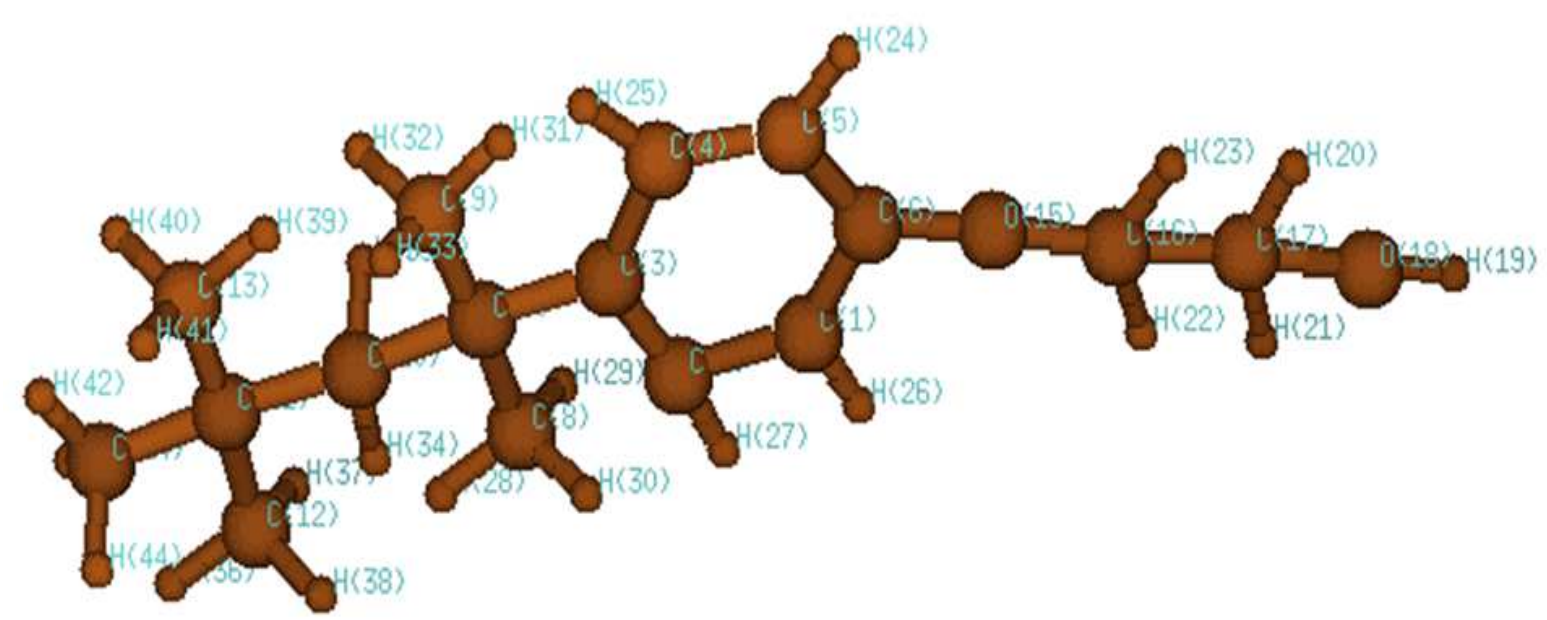

Figure 1: Optimized structure of surfactant triton X-114 structure; octyl phenol polyethylene glycol ether;Cloud Pointtemperature: 298.15K; Density at 298.15K: $1.052 \mathrm{gmL}^{-1}$; $\max$ (visible): $223 \mathrm{~nm}$; molecular weight: $537 \mathrm{~g} \cdot \mathrm{mol}^{-1}$.

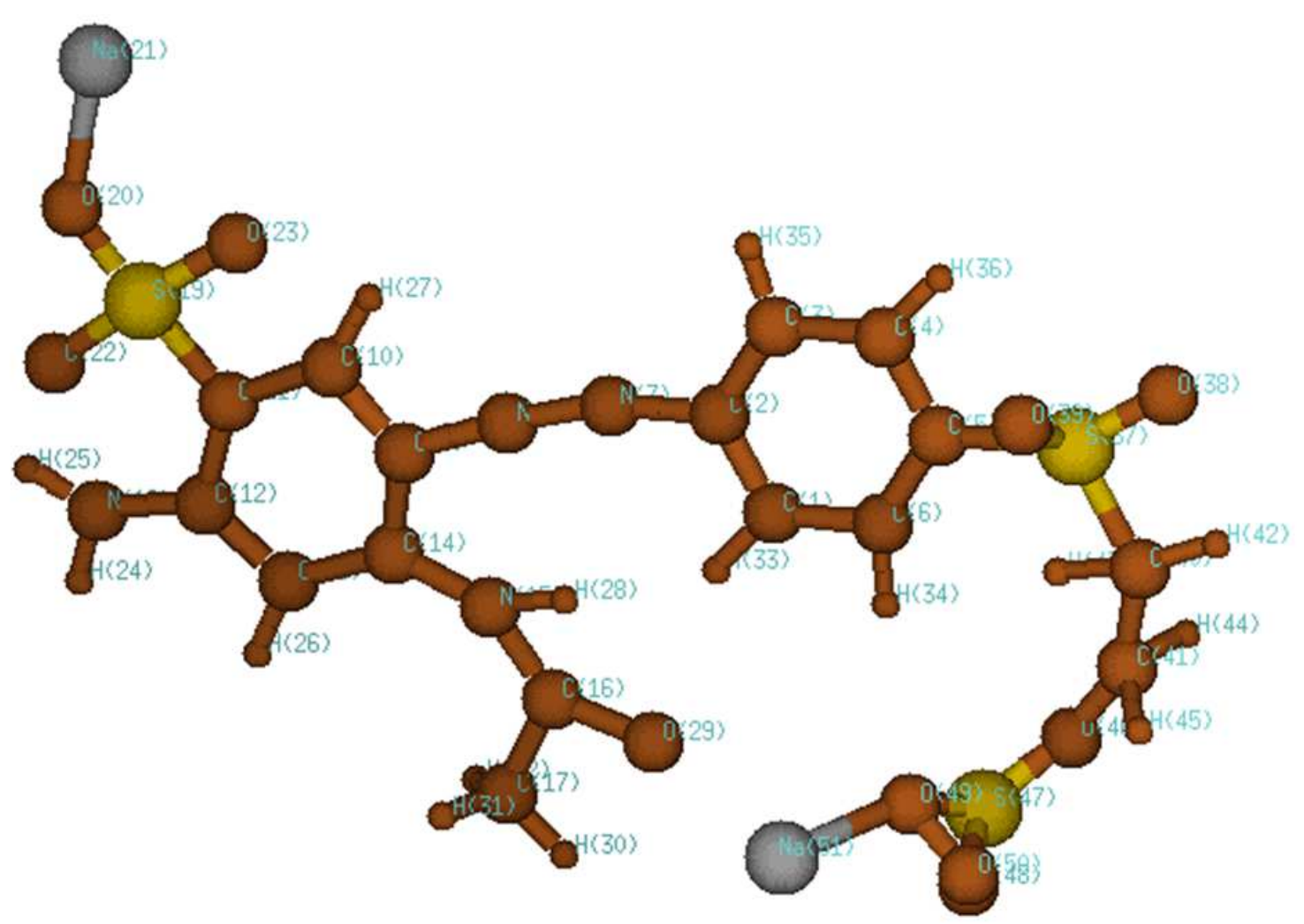

Figure2: Optimized structure of reactive orange 107 dyes; class: diazo; reactive group: vinyl sulphone; Density at $298.15 \mathrm{~K}: 1.7 \mathrm{~g} . \mathrm{mL}$ ${ }^{1}$; max (visible): $411 \mathrm{~nm}$; molecular weight: $566.49 \mathrm{gmol}^{-1}$. 


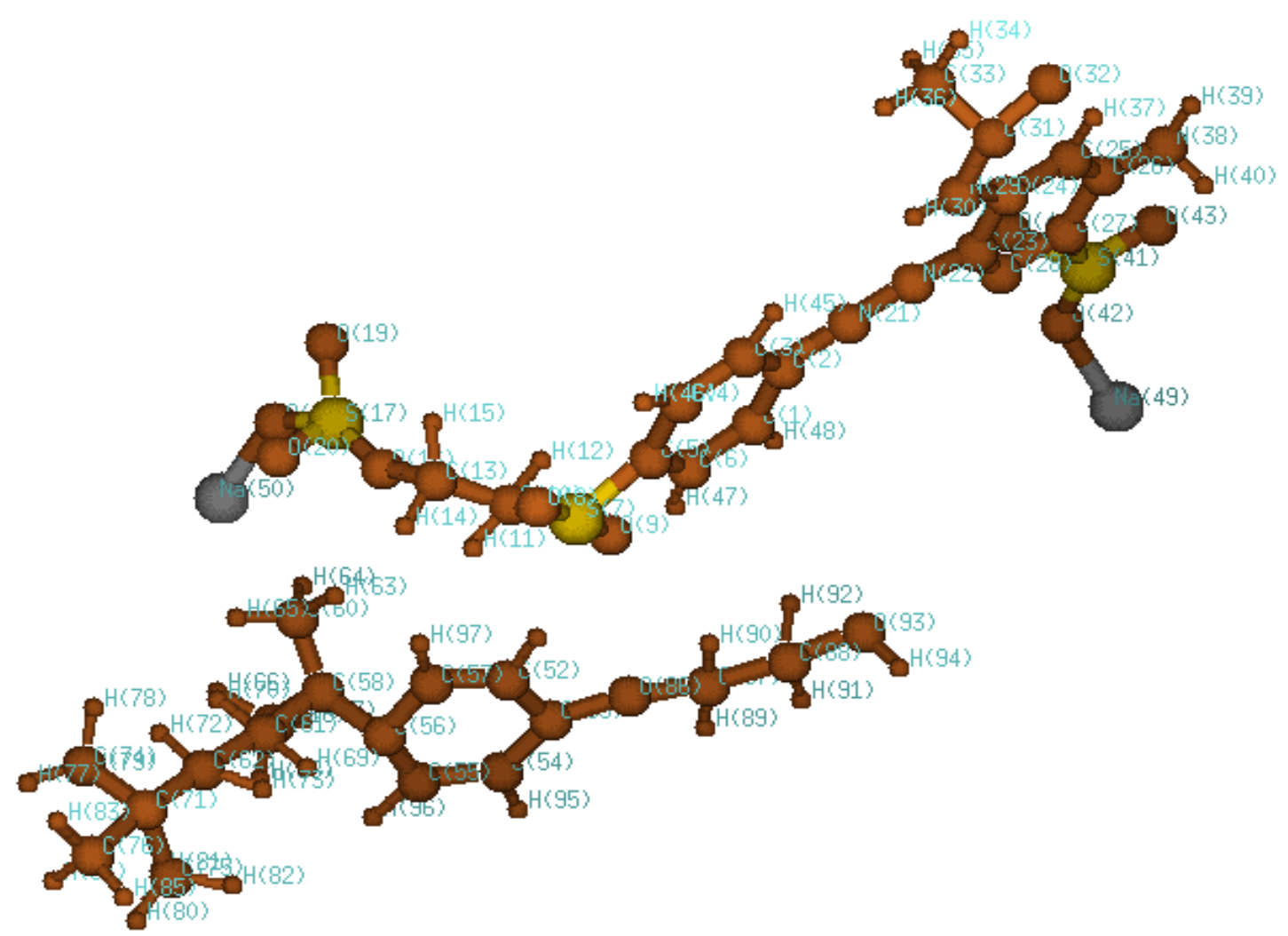

Figure 3: Optimized structure of complex formed between surfactant triton X-114+ reactive orange 104 dyes using $\mathrm{HF} / 6-31 \mathrm{G}^{*}$ level.

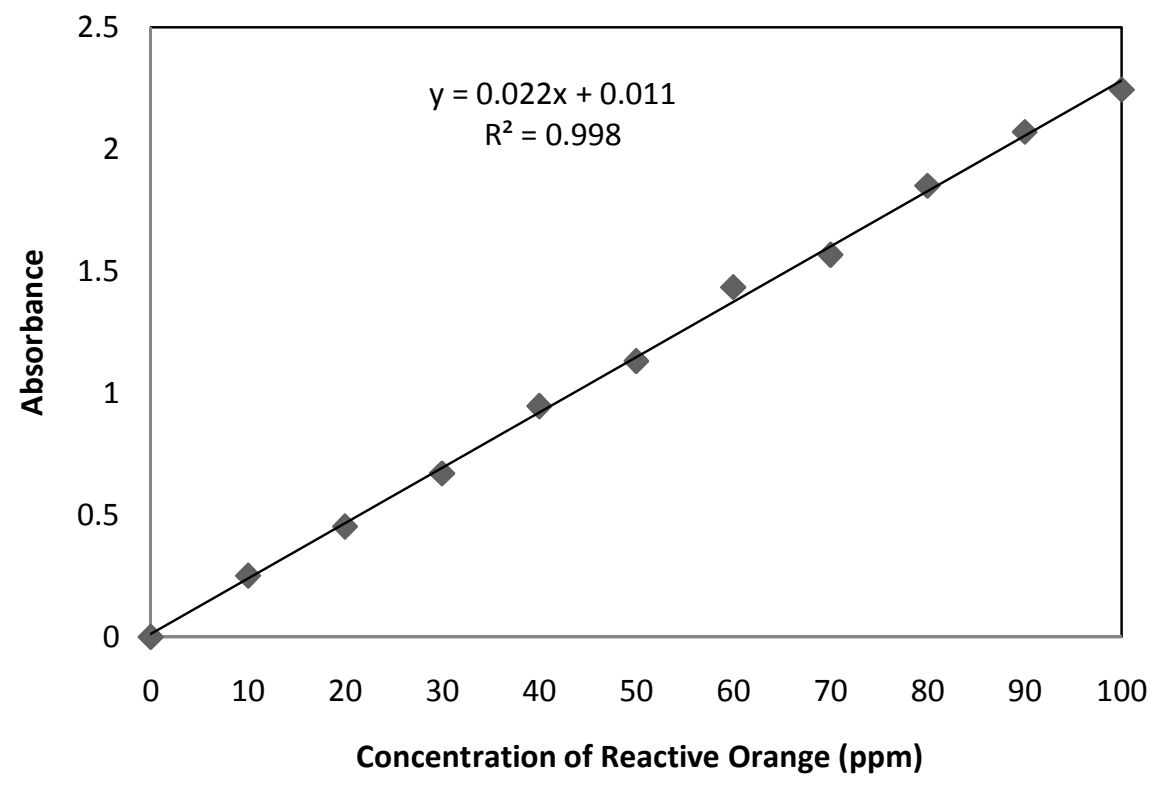

Figure 4:Calibration curve for Reactive Orange 107 dye 


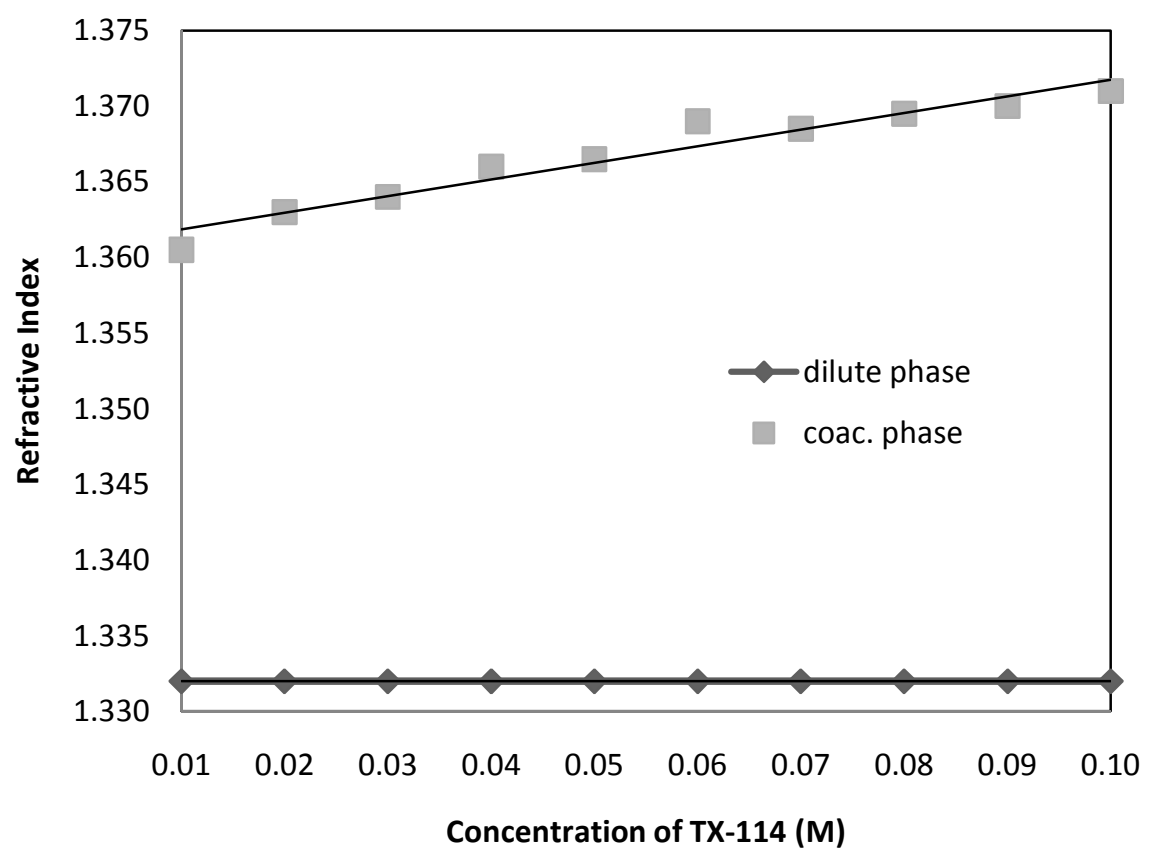

Figure 5: Variation of refractive index with TX-114 concentration for dilute and coacervate phase at 25ppm Reactive Orange concentration and at $313 \mathrm{~K}$ temperature

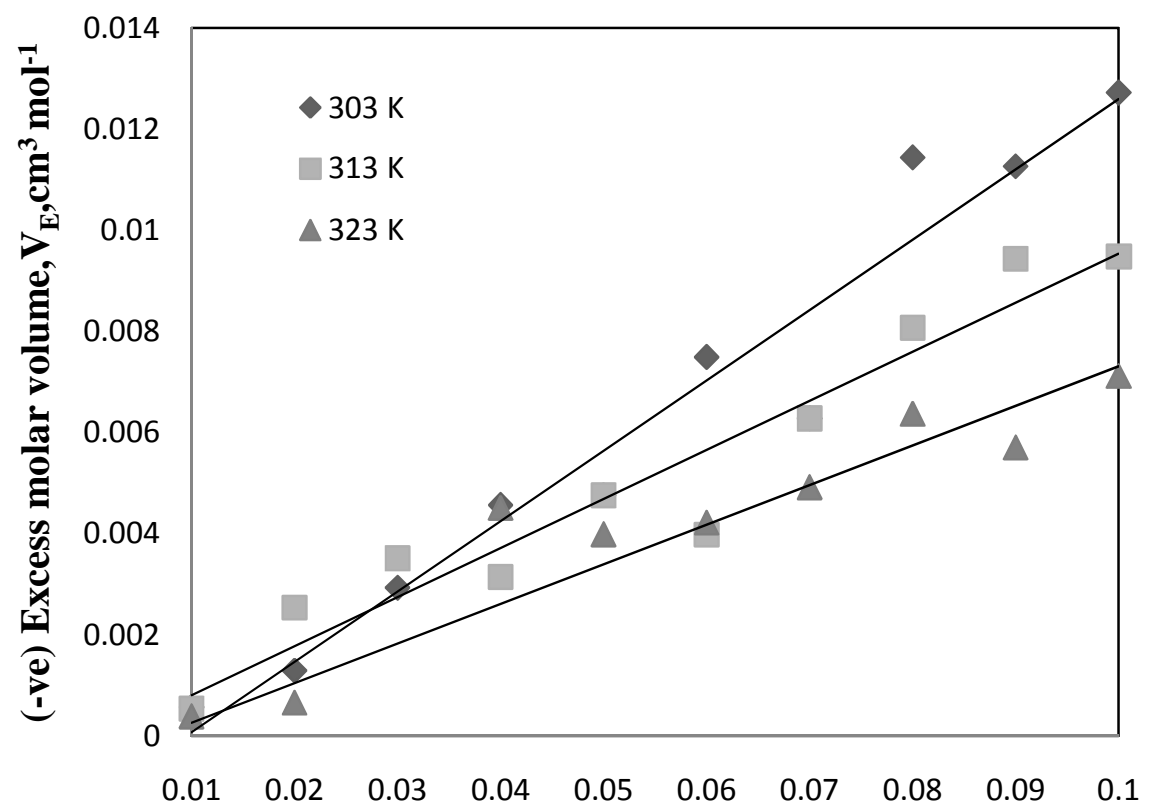

Concentration of TX-114 (M)

Figure 6: Variation of excess molar volume with temperature and surfactant concentration at $25 \mathrm{ppm}$ reactive orange concentration. 